\title{
Planning Age-Friendly Cities across the Globe
}

By Stephanie Firestone, Mildred Warner, and Xue Zhang

\section{"Urban planning as a field has failed to acknowledge our complicity in creating communities that are exclusionary; unless we acknowledge the problem, we will not be able to rectify it."}

$\mathrm{M}$ unicipal planners are those tasked to envision the physical form and future growth of the communities in which we live. However, increasing longevity makes this task more challenging than ever before, and many communities do not support the changing needs of residents across longer lifespans.

In the United States, this is due in part to a strict separation of land uses, rigid zoning rules, and other policies and practices that have guided the development of cities over a number of decades. As a result, automobile-centric suburbs created after World War II now house many older adults who live alone and are often socially isolated. Some live in large houses they cannot maintain, built with stairs and other design features no longer navigable due to disability or frailty, and located where inadequate public transportation makes it difficult for those who no longer drive to access supermarkets and other essential services and amenities.

Thus, community planners around the world must shift their approach to address the changing demographics in their communities. Yet many planners have not made this connection.
According to one US planner, "Urban planning as a field has failed to acknowledge our complicity in creating communities that are exclusionary; unless we acknowledge the problem, we will not be able to rectify it."

\section{Asking Planners Around the World} What can age-friendly community advocates do to foster awareness within the planning community - that is, to engage planners so that they incorporate aging considerations into their ongoing local and regional planning work? With an eye toward equipping advocates with this vital information, AARP teamed up with some other organizations to find out.

In fall 2017, AARP, together with the American Planning Association's International Division, Cornell University, and international consulting firm Arup, conducted a global survey of planners to assess how and why planners are (or are not) integrating the principles of Livable Communities for ALL Ages (LCA) ${ }^{1}$ into their planning work. Distributed through partner organizations and professional networks of planners, the survey garnered responses from 567 planners in 33 countries -72 percent from the
United States, 9 percent from Australia and New Zealand, 9 percent from Europe, 6 percent from Canada, and 4 percent from a Global South grouping that comprised Latin America, Asia, Africa, and the Middle East.

\section{What Motivates Municipalities}

First, we set out to understand why local governments took the steps necessary to make LCA a part of their practice; in other words, what were each town's or city's motivations (Figure 1)?

Interestingly, while we may presume that a tragic incident such as an older pedestrian fatality at a dangerous crosswalk is what spurs decision makers into action, this was ranked very low on the list of motivators (10 percent).

Notably, two key findings underscore the need for education. The top response was simply the "substantial growth in the aging population and the need to better serve this segment of the population" (72 percent). A number of respondents indicated that city planners and decisionmakers often underestimate the size of the rising older adult population and that they need "reminders of the statistical realities...in order 


\section{Figure 1: LCA motivations}

Percentage, $\mathrm{n}=335$

Substantial growth in aging population and need to better serve this segment of the population

Priority identified during a community planning process

A policy window that presented an opportunity

Local grassroots advocacy related to an issue

Building on interest or expertise of staff

An opportunity to leverage a project or program already underway

Policy or policies that mandate this perspective

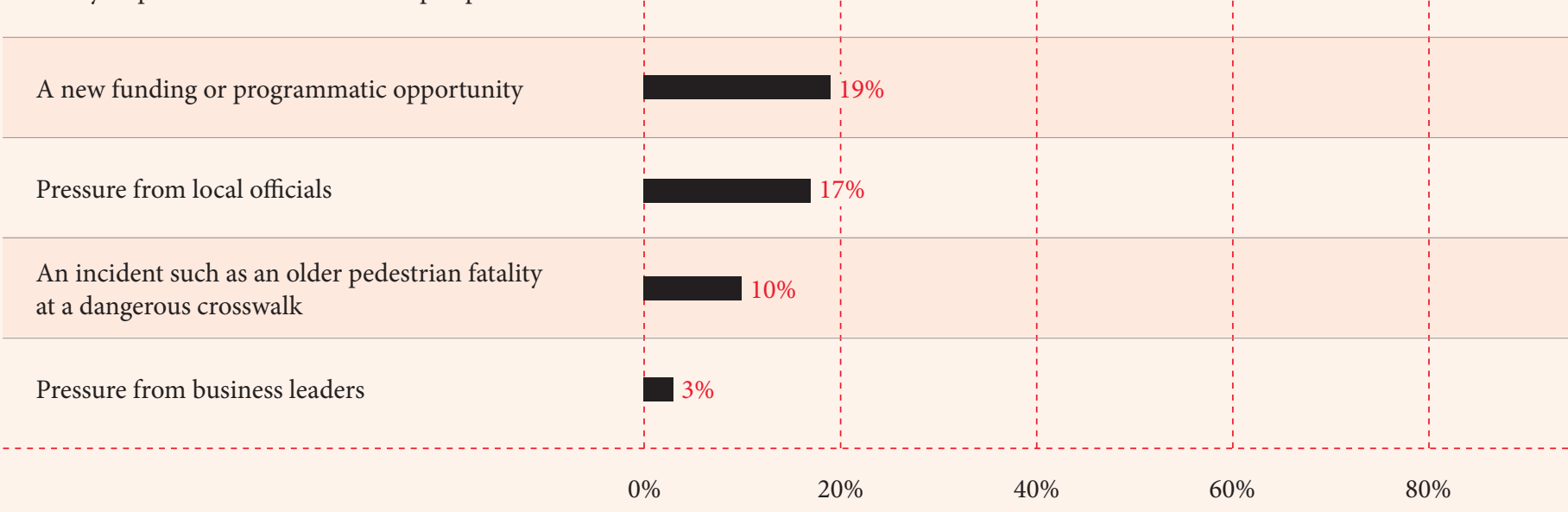




\section{Figure 2: LCA Incorporation in Planning Practices}

Percentage, $n=298$

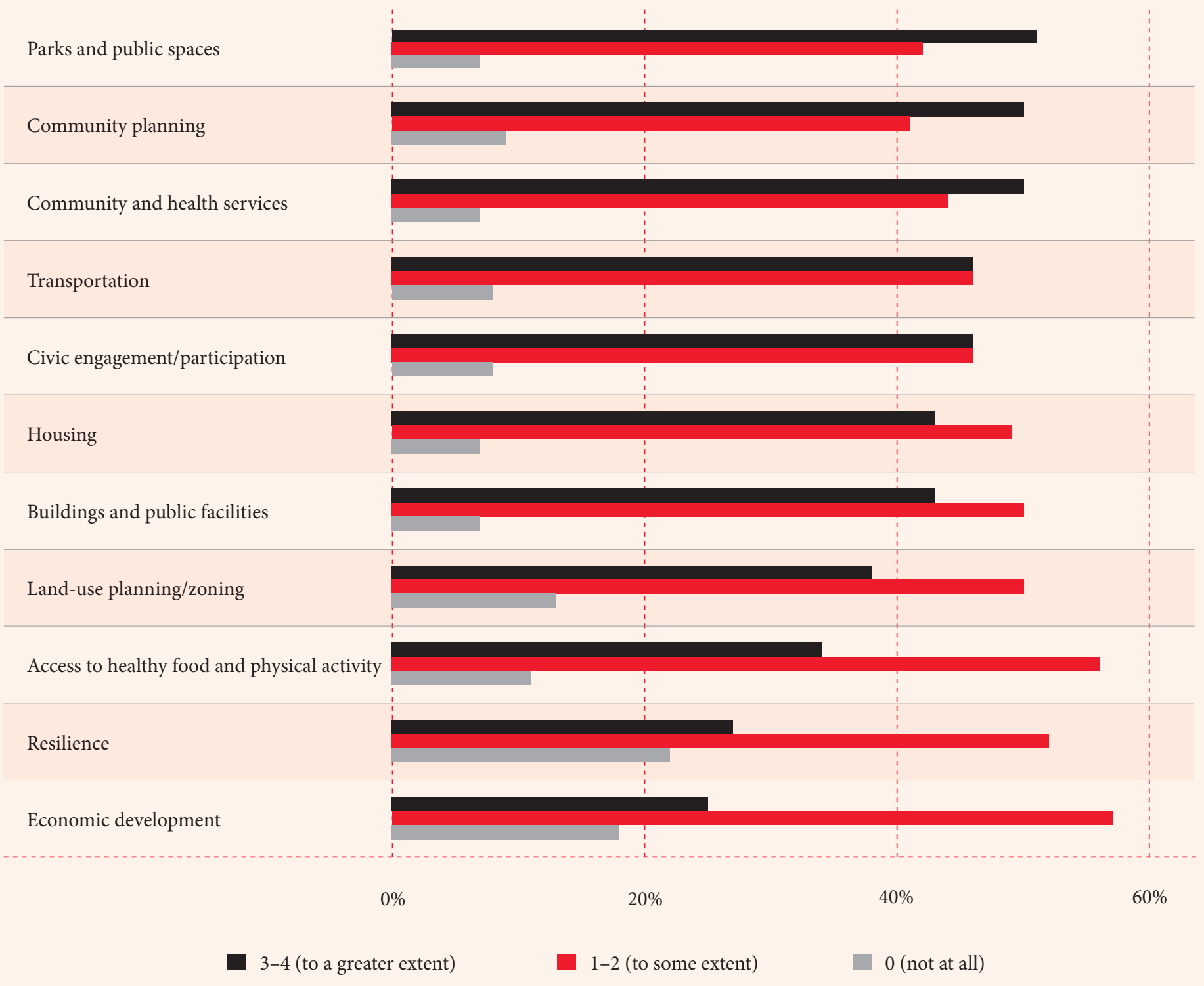




\section{"The generally low rating for} economic development planning that incorporates aging considerations suggests a significant missed economic
opportunity for local communities."

to spur policy directives for LCA-related planning and implementation."

The second most popular local government motivation for engaging in LCA was that it was a "priority identified during a community planning process" (50 percent). These top two findings illustrate the importance of educating local leadership about the facts and the implications of rapid population aging in their communities, as well as the significance of engaging the community in planning discussions to address these challenges.

The greatest regional distinction concerning motivations was that European respondents ranked "policies (i.e., national/regional) that mandate this perspective" second highest, while planners from all other countries ranked them eighth or ninth out of 11 possible motivations. Consistent with this finding is that Europe appears to benefit less from bottom-up approaches, with "local grassroots advocacy" ranking lower than in any other region.

\section{Individual Planner's Motivations}

Beyond municipal government engagement, we also asked individual planners what catalyzed their own efforts to incorporate an all-ages approach into their work. Responses proved enlightening. Social responsibility, for example, showed up a number of times. An Australian planner pointed to "a conscience and a value system that supersedes personal comfort at work, and a willingness to confront and be argued with," while a planner from Slovenia found motivation in the value of "intergenerational equity and quality of life for all."

US planners' motivations often reflected a personal vantage point. $A$ number of US planners alluded to the importance of age diversity and personal experience within the planning ranks - for example, "hiring older planners" as well as "planners [who] have aging parents and grandparents." One planner explained that "nothing beats personal experience with inaccessible buildings, poor public transportation, and roads that are hostile to pedestrians." Planners also stressed the need for compelling, real stories, including "narratives on how current land use practices impact real people's lives." Finally, a planner in the United Kingdom was motivated by "the quality of the resulting place." With an LCA approach, this planner said, "places are better for all people."

\section{Where Aging is Showing Up in Planning}

We also wanted to know specifically how an LCA approach is reflected in the work of town and city planning - that is, what, specifically, jurisdictions are doing to create more livable communities for all. Of the eight actions measured, more than half of planners reported the top two LCA-related actions were "performed a walkability/ accessibility assessment" (59 percent) and "incorporated LCA in major plans" (51 percent), such as a city's comprehensive plan or a pedestrian plan.
Interestingly, the third most common action, "adopted an actual policy that directly improves the quality of life for aging residents" (36 percent overall), had a significantly higher percentage among non-US respondents (66 percent). Understanding the root causes of this discrepancy will require further investigation.

The survey then examined the extent to which LCA principles were incorporated in 11 distinct areas of planning practice (Figure 2). The top three areas of LCA incorporation (50-51 percent each) were "parks and public spaces," "community planning," and "community and health services."

The second lowest ranking was for community "resilience" (27 percent) a notable disconnect given that older adults are among the most vulnerable populations in natural disasters. ${ }^{2}$

Surprisingly, at the very bottom of the rankings of planning practice areas where LCA principles were incorporated was "economic development" (25 percent). European planners, however, ranked this higher than respondents from other countries.

The generally low rating for economic development planning that incorporates aging considerations suggests a significant missed economic opportunity for local communities. In the United States, for example, more than 80 percent of household wealth is held by people over 50 , and this age group generates more than half of the country's consumer spending. ${ }^{3}$ This 


\section{Figure 3: Facilitating Practices}

Percentage, $n=296$

Colleagues support an all-ages approach to planning

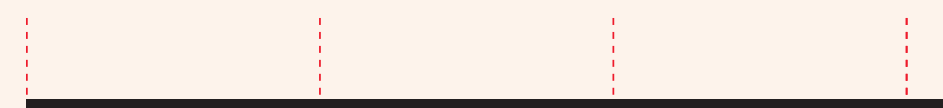

Workplace policies encourage an all-ages approach to planning

Periodic focus group interactions with aging population

Special project funding for LCA

Elected officials holding meetings with LCA focus

Client prioritizes LCA

Release time to work on LCA

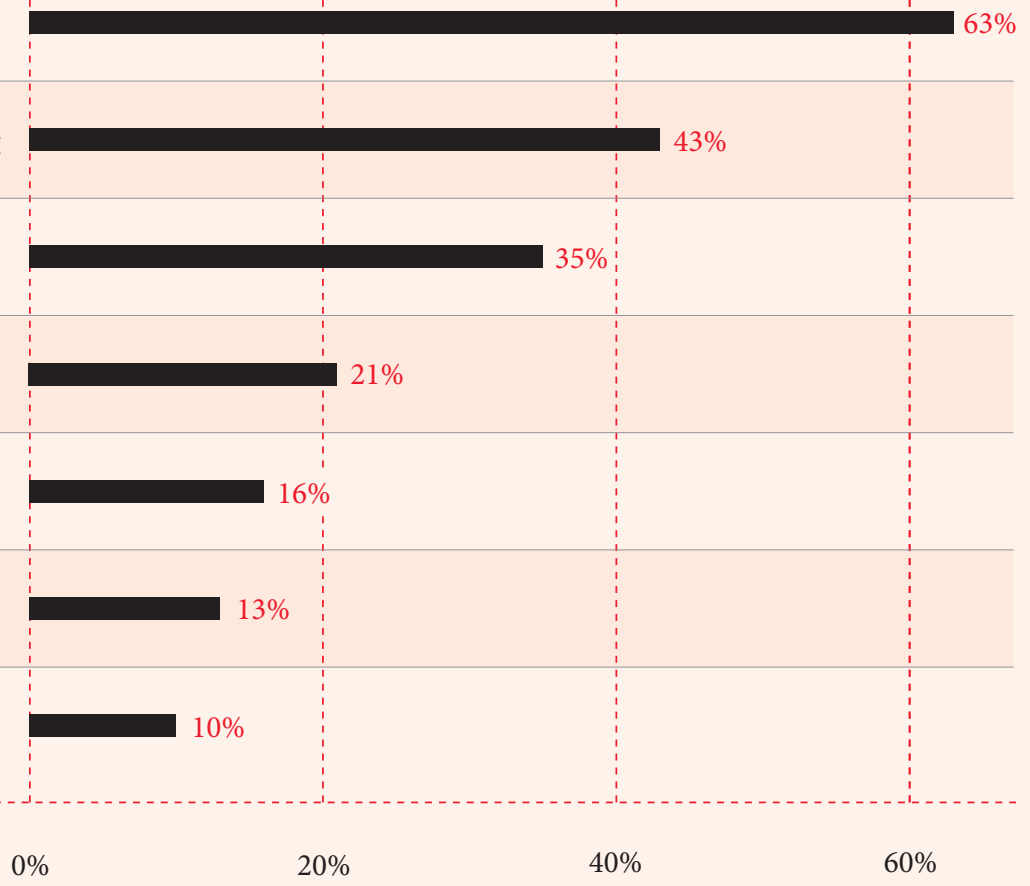

longevity dividend was apparent to one respondent, who said, "I would love to make LCA seen as more of an opportunity rather than a challenge that we need to find 'solutions' to."

\section{How to Hook Planners}

The importance of education and awareness related to workplace practices and strategies that facilitate engagement by individual planners continued to appear prominently in our findings.

The most effective of the eight strategies to encourage more planners to engage in LCA were "engaging elected officials, legislators to talk about LCA" (65 percent) and "hosting training or seminars on planning LCA" (56 percent overall, 75 percent in Canada). These findings again point to the critical need for age-friendly community advocates to educate both planners and elected officials about LCA, and to invite elected officials to participate in relevant public discussions. This will increase their understanding of the issues as they prepare for the event, provide an opportunity to potentially recruit them as allies, and allow for them to be held accountable later, if needed.

The survey asked planners what practices in their workplace facilitate their engaging an LCA approach in their work (figure 3). We found that "support from colleagues" (63\% percent) was 20 points higher than any other selection, followed by "workplace policies" (43 percent) and "periodic focus group interactions with aging population" (35 percent). While being given "release time to work on LCA" ranked lowest on the list (at 10 percent), this appeared to be a more common practice among planners in Europe (27 percent). Finally, the existence of "special project funding" for LCA was thought to be a key facilitator by only 21 percent of respondents a finding that perhaps alludes to the greater need for LCA facilitators that are systemic within the workplace and thus more sustainable over time.

In order to further interpret the survey results, we examined responses from a holistic perspective across the various survey questions. ${ }^{4}$ What emerged is that the two categories of "motivations" and "facilitating practices" in the workplace have the largest impact on the incorporation of LCA in the work of community planning, and that barriers encountered by planners, such as a lack of resources or more traditional planning approaches, do not appear to prevent action.

\section{Advocating in Your Local Community}

As community members and advocates seek to make their communities more 
"As community members and advocates seek to make their communities more age-friendly, it is important that they understand how to effectively engage local planners and other decisionmakers."

age-friendly, it is important that they understand how to effectively engage local planners and other decisionmakers. These survey results underscore that advocates need to educate these community influencers on the substantial growth in the aging population, and to use stories from actual residents to illustrate that growth's implications for their communities. They need to facilitate the involvement of all community members, including older adults, in community planning processes, and to engage experts on the needs of the aging population. And for the business community and other stakeholders, they should highlight the economic benefits of planning for all ages and encourage appropriate investments. Finally, they should leverage staff support and advocate for municipal policies that mandate an all-ages approach to local planning.

According to one US respondent, some planners realize that incorporating LCA practices "is the right thing to do and the smart thing to do; however, many elected officials and communities haven't caught on quite yet." Advocates can play a significant role in making that happen.
1. Livable Communities for ALL Ages are communities that are intentional about being great places for people to grow up and grow old, by ensuring appropriate physical infrastructures (e.g., housing, transportation, built environment, access to healthy foods) and social infrastructures (e.g., health care, support services, engagement opportunities) for residents throughout an expanding life course.

2. T. M. Al-Rousan, L. M. Rubenstein, and R. B. Wallace, "Preparedness for Natural Disasters among Older US Adults: A Nationwide Survey," American Journal of Public Health 104, no. 3 (2013): 506-11; C. J. Gaskin et al., "Factors Associated with the Climate Change Vulnerability and the Adaptive Capacity of People with Disability: A Systematic Review," Weather, Climate, and Society 9 (2017): 801-14.

3. W. He, M. Sengupta, V. A. Velkoff, and K. A. DeBarros, 65+ in the United States: 2005 [Washington, DC] US Department of Commerce, Economics and Statistics Administration, Bureau of the Census, 2005); M. E. Warner, G. C. Homsy, and L. J. Morken, "Planning for Aging in Place: Stimulating a Market and Government Response," Journal of Planning Education and Research 37 (2017): 29-42.

4. We ran a correlation analysis on motivations, facilitating practices, strategies of engagement, barriers, LCA actions, and incorporation.

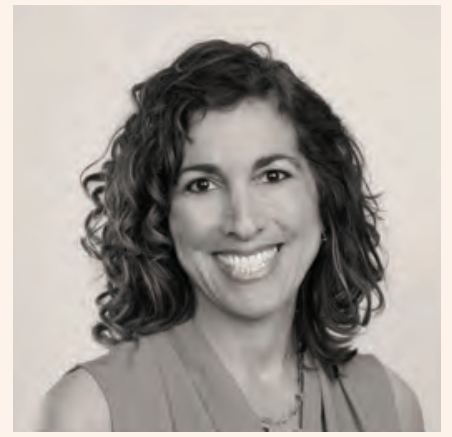

Stephanie Firestone SENIOR STRATEGIC POLICY ADVISOR, AARP

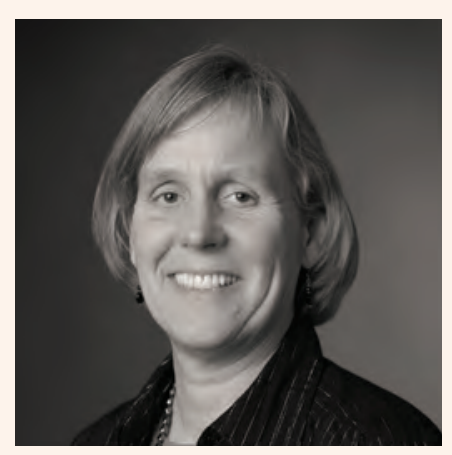

Mildred Warner PROFESSOR, DEPARTMENT OF CITY \& REGIONAL PLANNING CORNELL UNIVERSITY

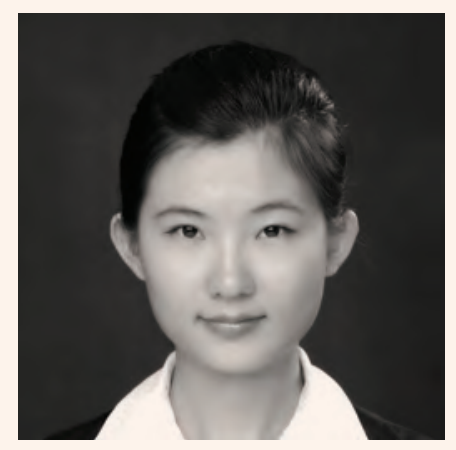

Xue Zhang PH.D. CANDIDATE, REGIONAL SCIENCE, DEPARTMENT OF CITY \& REGIONAL PLANNING, CORNELL UNIVERSITY 